\title{
NEW COMPOSITIONS WITH CROSSLINKED AND UNCROSSLINKED COLLAGEN POLYDISPERSIONS FOR SYSTEMIC TREATMENTS IN AGRICULTURE
}

\author{
MIHAELA-DOINA NICULESCU ${ }^{1}$, EDYTA GRZESIAK ${ }^{2}$, CARMEN GAIDĂU $^{1}$, \\ DORU GABRIEL EPURE ${ }^{3}$, CLAUDIU ŞENDREA ${ }^{1}$, MIHAI GIDEEA ${ }^{4}$ \\ ${ }^{1}$ INCDTP - Division: Leather and Footwear Research Institute, 93 Ion Minulescu St, district 3, \\ Bucharest,Romania,icpi@icpi.ro,mihaelaniculescu59@yahoo.com \\ ${ }^{2}$ Leather Industry Institute, 73, Zgierska St, Lodz, Poland \\ ${ }^{3}$ SC Probstdorfer Saatzucht Romania SRL, 20 Siriului St, sector 1, Bucharest, Romania \\ ${ }^{4}$ University of Agronomic Science and Veterinary Medicine, 59, Marasti St, district 1, Bucharest, \\ Romania
}

\begin{abstract}
The main property of collagen polydispersions is their molecular profile, dependent on both raw materials origin and the extraction process. The paper presents collagen extracts from leather byproducts, by thermal and enzymatic hydrolysis at alkaline $\mathrm{pH}$ with improved properties by additivation with glycerol and crosslinking with Tara tannin extract. Structural analysis by Dynamic Nuclear Magnetic Resonance Spectroscopy showed manifestations which may be attributed to the interaction of glycerol and Tara tanning extract with polypeptide chains and to the role of glycerol as plasticizer, partially compensated by the addition of Tara crosslinking. New combinations of crosslinked and uncrosslinked collagen polydispersions were applied in cereals and legume seed treatment, so as to provide free amino acid content immediately available for stimulation of germination and a layer of polypeptides that would slowly release amino acids for growth stimulation. The results were quantified by an increase in cereal seed germination of over $15 \%$ and a much more pronounced development of plants, which have reached lengths over $10 \%$ higher compared to untreated seeds. For the most of legumes, the new treatment led to development of total biomass (root and cotyledons) and to a higher permeability for the water imbibition of the seeds.
\end{abstract}

Keywords: collagen polydispersions, crosslink, structural analysis.

\section{INTRODUCTION}

Most collagen-based materials, in the form of gelatin, collagen hydrolysate, or complex 2D / 3D structures, such as membranes, hydrogels, aerogels, have been created for medical applications. However, due to the intrinsic or acquired functionalities, collagen materials have applications in many niche areas: in cosmetics, for the preparation of various make-up, cleaning and maintenance products, such as shampoo, creams, hair curling products (Langmaier et al., 2002); obtaining surfactants (Langmaier et al., 2002; Stepan et al., 2008); precipitation of polyphenols in the winemaking process (Ortiz-Barrera et al., 2015); obtaining food cling films (Wang et al., 2015); additivation of aminoplast adhesives to limit formaldehyde emissions from thermally treated adhesive films (Sedliacik et al., 2011; Niculescu et al., 2012).

Based on the results of studies that showed that protein extracts do not have toxic or genotoxic effects and do not adversely affect eukaryotic cells and the soil ecosystem (Corte et al., 2014), their applications were extended to the field of agriculture, particularly soil remediation (Zainescu et al., 2010) and fertilization of crops (Sirbu et al., 2009). The most recent studies have been focused on obtaining collagen hydrolysates from tanned leather by-products for the fertilization of horticultural crops (Gaidau et al., 2009, Pati et al., 2015), grain seed treatment to stimulate germination and reduce amounts of insecticide-fungicide (Gaidau et al., 2013), the fertilization of 
wheat and rice crops (Coelho et al., 2015), the use of fish skin collagen extracts to increase the yield of rape by stimulating growth and reducing silique dehiscence (Gidea et al., 2017), the use of bovine hide collagen hydrolysate in the foliar treatment of vines to alleviate the effects of iron deficiency due in particular to calcareous soils (Tudor et al., 2017).

In this research, collagen was recovered from secondary sources, namely bovine hide by-products from semiprocessed leather, by thermo-enzymatic processes. Compared to collagen functionalization models by cross-linking with glutaraldehyde, chitosan, cellulose, gluten, etc., proposed by other research (Oechsle et al., 2016; Tian et al., 2016), collagen extracts obtained in the form of gelatin and hydrolysates were combined with glycerol and Tara vegetable extract and new collagen-based compositions were created with favorable properties of increasing the germination rate of the seeds and plant growth.

\section{EXPERIMENTAL PART}

\section{Materials}

The bovine leather by-products was obtained from SC Pielorex SA, Romania with the following characteristics: $50-70 \%$ volatile matter, $0.5-12.5 \%$ total ash, $14-17 \%$ total nitrogen, aqueous extract $\mathrm{pH}$ value of 3.5-8.0, were obtained in Leather and Footwear Research Institute, Bucharest, Romania. Calcium oxide, acetic acid, glycerol were products of SC Chimopar SA Romania. Alcalase 2.4L was obtained from Novozymes Denmark.

\section{Procedures}

Bovine gelatin was obtained from half-processed bovine hide byproducts by thermal hydrolysis at $70-90^{\circ} \mathrm{C}, \mathrm{pH}=5.5-6.0$, duration 3-5 hours and concentration under vacuum at a ratio of $4: 1$. The collagen hydrolysate was obtained from wet blue shavings in a vessel equipped with thermal isolation, refrigerator, automated stirring, in water a solid to liquid ratio of $1: 5$ at $80^{\circ} \mathrm{C}$, with $10 \% \mathrm{Ca}(\mathrm{OH})_{2}$ during 5 hours. The solution was filtered, heated to $65-68^{\circ} \mathrm{C}, \mathrm{pH}$ adjustment at $8.5-9.0$ when $1 \%$ Alcalase $2.4 \mathrm{~L}$ was added and hydrolysis was continued for 3 hours. The enzyme deactivation was done at $90^{\circ} \mathrm{C}$ by stirring for $10 \mathrm{~min}$. (Niculescu et al., 2014).

The Tara vegetable extract was obtained by hydrolyzing Tara powder (Gaidau et al., 2014) in water a solid/liquid ratio of $1 / 4$ at $60-80^{\circ} \mathrm{C}$ for $1-2$ hours, centrifugation and vacuum filtration on cellulosic membranes.

The new compositions were made by continuously stirring the collagen polydispersions additivated/crosslinked with glycerol, tannin extract at $50-60^{\circ} \mathrm{C}$ for 40 90 minutes. The additive/crosslinker content is related to the moisture-free dermal substance content. For analytical reason cast films from the formulated compositions were dried in the forced convection oven.

\section{Analytical Methods}

The collagen polydispersions were analysed in terms of dry substance (SR EN ISO 4684:2006) and total ash (SR EN ISO 4047:2002) by gravimetric methods, total nitrogen and protein substance (SR ISO 5397:1996), aminic nitrogen (ICPI protocol) by 
volumetric methods, $\mathrm{pH}$ (SR EN ISO 4045:2008) by potentiometric method. The collagen additives interaction and its secondary structure were non-invasively investigated by NMR-MOUSE (Magritek Ltd). The tensile strength and elongation of films were investigated by Testing Machine H5KT.

\section{RESULTS AND DISCUSSIONS}

In this research, the following collagen extracts were developed: GB gelatin; H1 diluted hydrolysate, $\mathrm{H} 2$ diluted hydrolysate, with the chemical characteristics presented in Table 1.

Table 1. Characteristics of collagen extracts

\begin{tabular}{lcccc}
\hline \multicolumn{1}{c}{ Characteristics } & MU & Gelatin & \multicolumn{2}{c}{ Collagen hydrolysates } \\
& & GB & H1 & H2 \\
\hline Dry substance & $\%$ & 6.70 & 9.49 & 29.07 \\
Total ash & $\%$ & 1.04 & 4.02 & 6.05 \\
Total nitrogen & $\%$ & 17.73 & 16.30 & 16.31 \\
Protein substance & $\%$ & 99.64 & 91.61 & 91.66 \\
Amino nitrogen & $\%$ & 0.40 & 2.03 & 1.33 \\
pH & - & 5.81 & 8.19 & 8.07 \\
\hline
\end{tabular}

For the additivation of collagen extracts, a Tara vegetable extract was made with 5\% dry substance and 4 tanning substances which were combined in various formulations with collagen extracts to achieve polydispersions with film-forming properties in order to treat cereal and legume seeds.

Compositions of collagen-based polydispersions, in which the components are related to the collagen extract content, are shown in Table 2.

Table 2. Compositions of collagen-based polydispersions

\begin{tabular}{cccc}
\hline Protein polydispersions & $\begin{array}{c}\text { Collagen extract, } \\
\%\end{array}$ & \multicolumn{2}{c}{ Additive / crosslinker, \% } \\
Glycerol & Tara extract \\
\hline P1 & GB, 80 & 20 & - \\
P2 & GB, 85 & 10 & 5 \\
P3 & H2, 75 & 10 & 15 \\
\hline
\end{tabular}

Some of the compositions were cast into films and the structural and mechanical properties were studied, in order to extend the applications of these compositions and to create functional supports for very small seeds (to facilitate planting) or for different types of biodegradable packaging (e.g. for seedlings).

Currently, the richest and most complete structural information on organic compounds is provided by dynamic NMR spectroscopy (Badea et al., 2016). The NMR measurements of the additivated/crosslinked collagen films used basic gelatin (GB) as control. The relaxation times determined by NMR measurements are shown in Table 3 and exemplified in Figure 1. 
Table 3. Relaxation times for films

\begin{tabular}{cccc}
\hline Sample & T1 (ms) & \multicolumn{2}{c}{ Exponential T2 } \\
& & T2long (ms) & T2long (ms) \\
\hline GB & 77.09 & 1.29 & 0.18 \\
P1 & 40.14 & 8.71 & 2.04 \\
P2 & 51.39 & 3.45 & 1.26 \\
\hline
\end{tabular}

Decreasing the longitudinal relaxation time T1 can indicate a swelling of the films by mobilizing interstitial water and can be attributed to the interaction between the additive and the Tara tanning extract with the polypeptide chains. The transverse relaxation time $\mathrm{T} 2$ is a measure of the degree of mobility of the polypeptide chains: T2long - the amorphic area and the T2short - the rigid area. The growth tendency of T2 for P1, P2 films compared to raw gelatin (GB) indicates a peptide chain mobilization due to the plasticizing role of glycerol, partly compensated by the addition of Tara crosslinker.
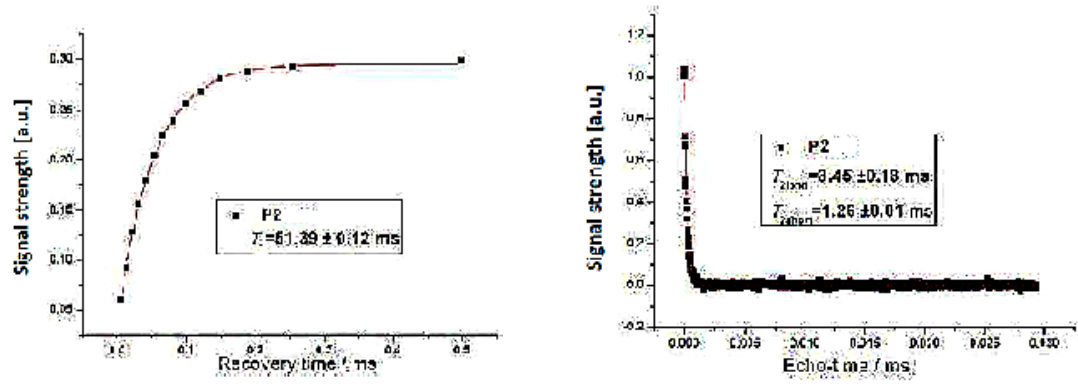

Figure 1. Curves of relaxing times $\mathrm{T} 1 ; \mathrm{T} 2$

This conclusion is supported by the results of physical-mechanical analyses of the two types of additivated/crosslinked collagen films, presented in Figure 2.

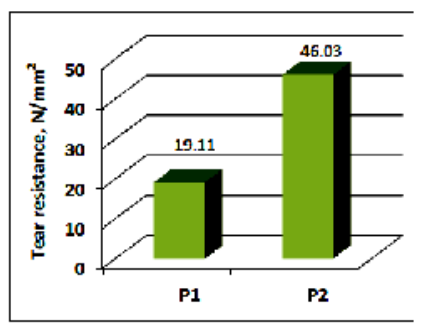

(a)

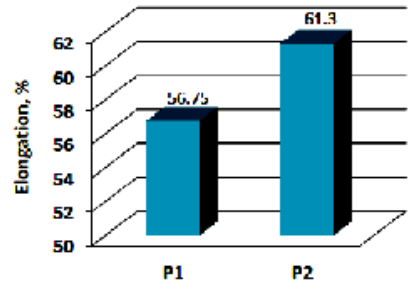

(b)

Figure 2. Mechanical properties of collagen films: (a) resistance; (b) elongation

Elongation and tensile strength tests highlight the improvement of the film's mechanical properties by cross-linking with Tara extract, tensile strength being about 2.5 times higher for the crosslinked film compared to the additivated film. 
Testing collagen-based compositions in cereal grain (wheat) treatment demonstrated an increase in germinative energy from $72 \%$ of the control treated with water (A) to $93 \%$ of the sample treated with $\mathrm{P} 3$ polydispersions. It was found that after 10 days from the onset of the experiment, all the plants remained viable, and those treated with P3 collagen polydispersions were more developed compared to the control, Figure 3.

Treatment of legume seeds (e.g. chickpeas, beans, soy, peas) with collagen polydispersions $(\mathrm{P} 3, \mathrm{H} 1, \mathrm{H} 2)$ resulted in $7-10 \%$ increase in germination rate, early plant growth and a more pronounced increase in total biomass (root and cotyledons) compared to untreated seeds, Figure 4.

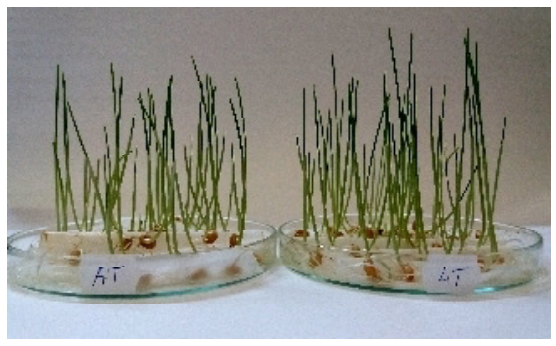

Figure 3. Development of wheat plants

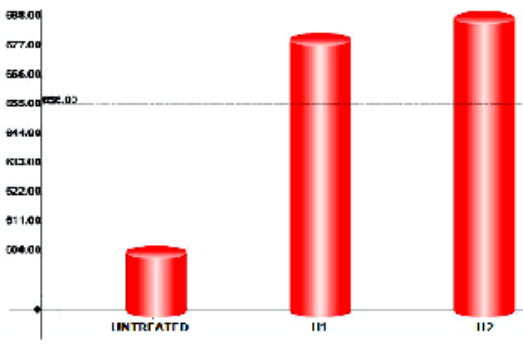

Figure 4. Biomass increase of peas

Early plant growth indicates greater permeability to water absorption. It was been noted that the stimulation of leguminous plant growth as a result of seed treatment with collagen polydispersions is influenced by the $\mathrm{pH}$ of the products used, the increase being higher in the case of treatment with $\mathrm{H} 2$ which has a slightly lower $\mathrm{pH}$ than $\mathrm{H} 1$.

\section{CONCLUSIONS}

- Collagen extracts have the ability to form films, whose flexibility, elasticity and strength characteristics can be modified depending on the degree of additivation with flexibility improvers and crosslinkers that enhance the resistance of films in order to adapt to application requirements.

- Treating cereal grains with collagen polydispersions leads to an increase in germination of approx. $25 \%$ and stimulation of plant growth.

- Treating legume seeds with collagen polydispersions results in early plant growth, due to faster water imbibition and a total biomass increase of approximately $15 \%$.

- Crosslinked and uncrosslinked collagen polydispersions presents properties that can be exploited to increase agricultural output.

\section{Acknowledgements}

This work was supported by a grant of the Romanian National Authority for Scientific Research and Innovation CCCDI - UEFISCDI, project no. PN-III-P3-3.5EUK-2016-0029/COLL-RAPE and a grant of Core Program, project no. PN 18.23.01.04. 


\section{REFERENCES}

Badea, E., Sendrea, C., Carsote, C., Adams, A., Bluemich, B., Iovu, H. (2016), "Unilateral NMR and thermal microscopy studies of vegetable tanned leather exposed to dehydrothermal treatment and light irradiation", Microchemical Journal, 129, 158-164, https://doi.org/10.1016/j.microc.2016.06.013.

Coelho, L., Ferreira, M.M., Bastos, A.R.R. et al. (2015), "Leather Industry Waste as a Nitrogen Source for Wheat and Rice in Succession", Revista Brasileira de Ciencia do Solo, 39(5), 1445-1455, https://doi.org/10.1590/01000683rbcs20140608.

Corte, L., Dell'Abate, M.T., Magini, A. et al. (2014), "Assessment of safety and efficiency of nitrogen organic fertilizers from animal-based protein hydrolysates - a laboratory multidisciplinary approach", Journal of the Science of Food and Agriculture, 94(2), 235-245, https://doi.org/10.1002/jsfa.6239.

Gaidau, C., Niculescu, M., Stepan, E., Taloi, D., Filipescu, L. (2009), “Additives and Advanced Biomaterials Obtained from Leather Industry By-products", Revista de Chimie, 60(5), 501-508.

Gaidau, C., Niculescu, M., Stepan, E., Epure, D.-G., Gidea, M. (2013), "New Mixes Based on Collagen Extracts with Bioactive Properties, for Treatment of Seeds in Sustainable Agriculture", Current Pharmaceutical Biotechnology, 14(9), 792-801, https://doi.org/10.2174/1389201014666131227112020.

Gaidau, C., Simion, D., Niculescu, M.D., Paun, G., Popescu, M., Bacardit, A., Casas, C. (2014), "Tara Tannin Extract Improvement. Part I: Extraction and Concentration Through Membranary Filtration Techniques", Revista de Chimie, 65(8), 929-933.

Gidea, M., Stepan, E., Enascuta, E.C., Gaidau, C., Niculescu, M.D., Epure, D.G., Cioineag, C., Sandulescu, E.B., Epure, L.I. (2017), "Researches on the biostimulating and antidehiscent effect of products based on fish collagen crosslinked to rape crop", Journal of Biotechnology, 256, Supplement, S100.

Langmaier, F., Mladek, M., Kolomaznik, K., Sukop S. (2001), "Collagenous Hydrolysates from Untraditional Sources of Proteins", International Journal of Cosmetic Science, 23(4), 193-199, https://doi.org/10.1046/j.0412-5463.2001.00081.x.

Langmaier, F., Mladek, M., Kolomaznik, K., Maly, A. (2002), "Degradation of Chromed Leather Waste Hydrolysates for the Production of Surfactants", Tenside Surfactants Detergents, 39(2), 31-34.

Niculescu, M.D., Sedliacik, J., Gaidau, C., Jurkovic, P., Matyasovsky, J. (2012), "Complementary methods for recovery and valorisation of proteins from chrome leather wastes", Leather and Footwear Journal, 12(2), 85-100.

Niculescu, M.D., Gaidau, C. (2014), New Collagen Extracts Conditioning for Applications in Crop Protection Against Pests", Revista de Chimie, 65(12), 1457-1461.

Oechsle, A.M., Häupler, M., Weigel, F., Gibis, M., Kohlus, R, Jochen, W. (2016), "Modulation of extruded collagen films by the addition of cogelling proteins", Journal of Food Engineering, 171, 164-173, https://doi.org/10.1016/j.jfoodeng.2015.10.004.

Ortiz-Barrera, E., Macias-Carranza, V., Cabello-Pasini, A. (2015), "Precipitation of wine polyphenols using collagen from fish skin and fish swim bladder", CyTA-Journal of Food, 13(4), 597-602.

Pati, A., Chaudhary, R. (2015), "Soybean plant growth study conducted using purified protein hydrolysatebased fertilizer made from chrome-tanned leather waste", Environmental Science and Pollution Research, 22(24), 20316-20321, https://doi.org/10.1007/s11356-015-5549-5.

Sedliacik, J., Matyasovsky, J., Smidriakova, M. et al. (2011), "Application of collagen colloid from chrome shavings for innovative polycondensation adhesives", Journal of The American Leather Chemists Association, 106(11), 332-340.

Sirbu, C. et al. (2009), "Fertilizers with Protein Chelated Structures with Biostimulator Role", Revista de Chimie, 60(11), 1135-1138.

Stepan, E., Velea, S., Gaidau, C., Filipescu, L., Ghiga, M.D., Radu, A.C. (2008), "Surfactants obtained from unconventional resources", 7th World Surfactants Congress, Paris, France, CESIO 2008.

Tian, Z., Duan, L., Wu, L., Shen, L., Li, G. (2016), "Rheological properties of glutaraldehyde-crosslinked collagen solutions analyzed quantitatively using mechanical models", Materials Science and Engineering, 63, 10-17, https://doi.org/10.1016/j.msec.2016.02.047.

Tudor, E., Cioroianu, T., Sirbu, C., Dumitru, M., Grigore, A., Parvan, L., (2017), "Fertilizer for the Treatment of Iron Chlorosis. Physico-chemical and agro-chemical properties", Revista de Chimie, 68(1), 65-68.

Wang, L.F., Rhim, J.W. (2015), "Preparation and application of agar/alginate/collagen ternary blend functional food packaging films", International Journal of Biological Macromolecules, 80, 460-468, https://doi.org/10.1016/j.ijbiomac.2015.07.007.

Zainescu, G., Voicu, P., Gherghina, A., Sandru, L. (2010), “Application of tannery organic wastes in degraded soils remediation”, Journal of Biotechnology, 150, 290-290, https://doi.org/10.1016/j.jbiotec.2010.09.233. 